\title{
Delfín de Eleguá
}

Por Eliseo Altunaga ${ }^{1}$

Después de arengar a sus hombres, el amo volvió hacia la casona de campo. Circulaban, entre la negrada, hojas de papel con dibujos y versos incitándole a la rebelión. Las preparaban los ingleses en Jamaica y, con sus espías, las distribuían entre los barracones de la región. "Con eso pretenden derrocar a España, invadir la isla de máquinas, pero aquí manda y mandará la corona española y no la inglesa". Subió los secos escalones de sabicú. Se volvió para mirar a sus mayorales. Le pareció que estaban más relajados, incluso, Miguel reía.

A mediados de zafra el foete sonaba en el cañaveral y a algún negro le daba por escapar. El rancheador lo cazaba vivo. En la plazoleta del batey, delante de toda la dotación, se castraba, se le cortaba la nariz y las orejas y se que quemaban los pies con tizones. Se prolonga el suplicio durante dos días. Por último, alzada sobre un madero se dejaba podrir la cabeza hasta que brillara de pulido el cráneo. Por eso la fuga no preocupa tanto al amo. Lo peligroso eran los negros de la ciénaga. Armados de machetes. Acostumbrados a matar y a vivir libres. Lanza el tabaco al suelo y entra a la casa. Coloca el látigo y el sombrero en una mesita de caoba. Mira a su mujer que seguro ya sabe la noticia. Detalla su cara fresca, su pelo negrísimo, los ojos grandes, la piel pálida y limpia. Cuando se casó, había calculado que Mariana no soportaría vivir alejada de la ciudad, las amistades, las tertulias nocturnas y la misa en la Catedral. Él le sugirió que viniera sólo de tarde en tarde a la casona de campo. Pero ella quiso ser el ama y lo era. Eso trastocó sus planes. Con su matrimonio había duplicado sus tierras. Y con los oficios de su suegro podía vender el azúcar sin pasar por el monopolio español.

-Irma tráeme algo que me saque este calor del cuerpo -gritó el amo mientras evadía la mirada de Mariana. Se secó la frente con un tosco gesto.

-Se escapó. La culpa es tuya por no tratarlo como un esclavo. Si no fuera por la zafra yo mismo hubiera ido a cazarlo con los perros y el alazán. Mañana tengo aquí al rancheador.

\footnotetext{
${ }^{1}$ Eliseo Altunaga (Camagüey, Cuba, 1941). Escritor y guionista cinematográfico. Ha publicado los libros Todos mezclados (1984), Canto de gemido (1988), A media noche llegan los muertos (1998), En la prisión de los sueños (2003), Las negras brujas no vuelan (2005) y Lágrimas negras (2016).
} 
Mariana palideció. Delfín era su esclavo personal. El amo no tenía ningún derecho sobre él. Mariana sabía que el amo lo había echado aquella tarde para mortificarla. Desde hacía semanas buscaba un pretexto para enviarlo al barracón. Siempre había dicho que su figura era más para las labores del campo que para las faenas domésticas. Pero ella nunca pensó que el amo se atreviera a tanto. El esclavo, armado de un cuchillo curvo de doble filo, era su sombra. Podía llamarlo a cualquier hora. Salía tras ella, a unos metros, en las tardes en que ella buscaba la soledad en los montes cercanos a los cañaverales.

Al amo poco le había importado Delfín. Su suegro había insistido en que lo llevara con Mariana para la casona (incluso algunos murmuraban que era hijo del viejo). Pero luego, cuando el amo abandonó las almidonadas sábanas de Mariana, comenzó a disgustarle la atenta mirada del esclavo.

-Agua de coco con miel para sacarle el calor del cuerpo, amo.

Él miró los ojos carmelitas de Irma. Hasta que Mariana tomó la administración doméstica, todos temían a Irma porque la casona había escuchado al amo, en la oscuridad de la noche, rogar cosas que solamente ella sabía realizar.

El amo bebió dos grandes sorbos y lanzó una carcajada que recorrió la casa. La mezcla, preparada con una buena dosis de aguardiente le encendía las entrañas. Cuando terminó de reír, ya Mariana estaba en su habitación.

Como si fuera verano, el calor acosa a la casona. Acostada sobre la cama, Mariana trata de concentrarse en la lectura de un libro al que el sudor empapa las páginas:

Esta visión quiso el Señor la viene así. No era grande, sino pequeño, hermoso mucho, el rostro tan encendido que parecía de los ángeles muy subidos, que parece todos se abrazan. Debe ser de los que llaman querubines, que los nombres no se lo dicen; más bien veo que en el cielo hay tanta diferencia de unos ángeles a otros, y de otros a otros, que no lo sabría decir. Veíales en las manos un dardo de oro largo, $\mathrm{Y}$ al fin del hierro me parecía tener un poco de fuego. Este me parecía meter en 
el corazón algunas veces, y que me llegaba a las entrañas. Al sacarle, me parecía que las llevaba consigo, y me dejaba toda abrasada en amor grande de Dios.

Suda por cada uno de los poros con un sudor grueso, como si toda el agua quisiera escapar de su piel. "Era tan grande el dolor, que me hacía dar aquellos quejidos; y tan excesiva la suavidad que me pone este grandísimo dolor, que no hay desear que se quite, ni se contenta el alma con menos que Dios". El sudor le rueda por la frente, por los ojos, le empapa los pómulos, le pega el cuerpo a la bata de hilo bordado que reproduce sus formas. "No es dolor corporal sino espiritual, aunque no deja de participar en el cuerpo algo"... Siente como si le faltara el aire, se agita. Traga y por su garganta se desliza una especie de cola viscosa. Se incorpora. Intenta sentir alivio. No sin esfuerzo llama a la esclava que aparece enseguida.

-Negra, ¿qué le diste al amo? ¿Qué le diste que saca el calor del cuerpo?

La cara de Irma trata de contener la expresión que delatan los grandes ojos carmelitas. El recuerdo de una negra embarazada, en el cepo, engarrotada de dolor, con la espalda destrozada, la estremeció. Mediante buena suerte y muchos ardides había podido evadir los castigos, pero sabía que si el ama lo había decidido pasaría los mismos tormentos que Delfín.

Tartamudeó al explicar la forma en que hacía la bebida que sólo tomaban los esclavos y los hombres. Tuvo que calmarse para describir que se preparaba con miel, agua de coco, aguardiente y algunas yerbas que solo conocen los yerberos viejos. No con poco miedo, esperando una trampa, aún tensa, luego de escuchar la respuesta, preparó un coco bien cargado para complacer a su ama. Como hacía su marido. Mariana se empinó la fruta dejando que le inundara la garganta. La fresca mezcla le humedece la boca, le suaviza los labios, se desborda, corre entre sus senos... suspira satisfecha. Se siente mejor. Tal vez más tranquila. Hasta se anima a concebir que escucha el eco de un murmullo rítmico y cadencioso, una suerte de rezo cantado, que, suavemente, ocupa la habitación. De improviso la ronca voz del amo interrumpe el embeleso de Mariana.

-Irma, ven acá. ¿Dónde diablos te has metido?

-Enseguida, su mercé.... 
Mariana entrega el coco vacío y la esclava se retira diligente, tratando de contener la obstinada sonrisa que le provoca un pensamiento poco inocente.

El ama queda sola y tras la sensual sombra de la esclava, regresa el eco del rezo, largo, continuo, suave...

El barracón está intranquilo. Las mujeres no zurcen los jirones de ropa apergaminada de sudor y grasa, con las cuales los hombres tratan de cubrirse de las filosas hojas de caña. En el semioscuro recinto, los jóvenes especulan sobre los cimarrones de quienes se asegura que han cruzado la ciénaga y se mueven entre los cañaverales, con la ayuda de un guía, en grupos de a cuatro. Incrédulos y desconfiados, los más viejos, absortos en una voz constante, recurren al único método seguro: hacen llamadas a papá Legbá para que les abra los cien caminos a su hijo y se los cierre al rancheador, hasta que el muchacho llegue al pantano, donde los perros quedan locos.

Para todo el barracón está fresco el bocabajo y el cepo, las huellas de los latigazos, la risa de los mayorales y contramayorales. Luego, su figura en el cañaveral, con las heridas abiertas, sin comer, obligado a trabajar hasta desfallecer, con las manos en carne viva. Fresca aún está la cadena de humillaciones que soportó en silencio durante semanas. Sólo los más viejos, los que guardan los secretos y las lenguas de África; los de ojos agudos y ritos repetidos en barcos y costas, los que no sonríen y tienen la cara como de piedra: los que por las tardes miran siempre al Este, a donde algún día volverán; los que nunca han aprendido la lengua de los amos; sólo ellos sabían en lo que aquel esclavo se estaba convirtiendo. Por eso fueron ellos los que comenzaron el canto a papa Legbá y quemaban sus pocas horas de suelo en las más antiguas canciones de guerra y protección; por eso el canto tenía ansiedad que lo hacía infinito; por eso lo llamaban hijo de los orishas; por eso luchaban contra el miedo y el cansancio, como si supiesen que los está escuchando, de pie, sobre la noche que abraza la vida.

Por su parte, lo más jóvenes, los que fraguaron el plan junto a Delfín, se miran en silencio y se repiten, mentalmente, con minucioso afán, cada detalle de la acción. Los cimarrones están cerca y Delfín el nuevo cimarrón, tal vez les habrá trasmitido ya sus planes. Entre trago y trago de aguardiente robado, los jóvenes del barracón, tensos, repiten con los viejos el insistente estribillo: "Papá Legbá, ábrele los caminos". 
Mariana toma el curvo cuchillo. Con delicadeza, saca la hoja de la funda. Es una daga fabricada por herreros moros y vendida por un judío a su padre. El mango, de tarro y metal, en una de sus caras, reproduce la nítida silueta de un cuervo. Deja que la hoja se deslice en la funda.

El vendedor había explicado los poderes orientales y cristianos que el ave representaba y había hecho la narración (quién sabe si inventada) de un rito, durante el cual, con destreza, un hombre abría con el arma a un caballo en dos mitades, con un solo bárbaro golpe. Vuelve a sacar suavemente la hoja. Más interesado en el filo de la daga que en la mística sobre el cuervo, el padre adquirió el arma y se la regaló a Delfín.

Entra la hoja en el estuche. Desde el día en que le regalaron el arma, el esclavo la había convertido en una peligrosa prolongación de su cuerpo. Mariana recorre con los dedos la curtida superficie del estuche que persigue la forma de la hoja. Escucha a lo lejos la risa de Irma. Vuelve a acariciar la funda que se le antoja de la misma textura tiznada piel del esclavo. La risa de Irma insiste en molestarla. Coloca el arma en la mesa de noche, sobre el libro de Santa Teresa de Jesús. A través de la ventana ve un pedazo de cielo estrellado. Una brisa inesperada hace más evidente el rezo que desespera la noche. El calor martiriza cada uno de sus poros. Se mete dentro de la bañadera. El agua fresca cubre el cuerpo tibio. El amo estuvo a punto de llamar al mayoral y acabar con la cantaleta que se repite en el barracón. Pero el aguardiente con agua de coco y los ardides sexuales de Irma, lo fueron alejando el mundo del batey, de los abolicionistas, de los vendedores ingleses, del precio del azúcar, de su mujer y del esclavo escapado. Irma lo enloquecía hasta que sólo quedaba en sus sentidos la forma exacta de sus ojos, la firmeza de sus carnes, la presión palpitante de calor. Como un contrapunto, los sonidos de la noche se mueven en torno a la bañadera. El monótono lamento del barracón se confunde con las lejanas risas y los quejidos. Lentamente, Mariana comienza a rezar:

-Padre nuestro que estás en los cielos, santificado sea tu nombre, y hágase tu voluntad, así en la tierra como en el cielo.

-Papá Legbá, ábreles los caminos -repiten en el barracón.

El inusitado conjunto de sonidos, unido a su rezo, despierta en ella un delicado placer que, paulatinamente se va aficionando, como un solista hindú en la búsqueda de la repetición del tema. Sus músculos se destensan y el calor que les sale de las entrañas comienza a 
repartirse por todo el cuerpo en un suave cosquilleo. Así va quedando extasiada en el agua fría, en un largo letargo.

En el barracón, el lamento ha cesado. En su lugar, tras la puerta, se encuentra el travieso Eleguá y todos se preparan para honrar a este orisha inquieto, revoltoso, hijo de la suerte y el azar.

Sólo ahora advierte que se ha quedado dormida. No escucha el lamento del barracón ni la risa lejana. Trata de organizar sus pensamientos y adaptarse a la escasa luz. Levanta la vista y se encuentra con la figura de Delfín, su fiel esclavo. Se ha puesto el sombrero del amo, fuma uno de sus tabacos y le hace un simpático gesto con los brazos cruzados por las muñecas, subiéndolos y bajándolos en dirección al pubis, como el travieso Eleguá. Está vidriado de sudor e iluminado por un inusitado resplandor rojizo. Ella sonríe. Como de costumbre ante su presencia se siente segura de todo mal. Le extiende la esponja. Como de costumbre, él la toma y le frota la espalda con la presión exacta. Luego, con la maestría inimitable, le acaricia todo el cuerpo, la acuesta boca arriba sobre el agua y hunde la inesperada hoja curva sobre el pecho de la joven que tal vez cree que aún sueña, mientras el agua se tiñe de púrpura y las lenguas de fuego comienzan a devorar los cañaverales y los barracones sublevados, sobre los que se levantan dos enormes nubes de humo negro, como las alas de un cuervo mitológico. 